\title{
DESIGN ANALYSYS OF DISK BRAKE USING NEWLY DEVELOPED STIR CASTED MASTER ALLOY DISK FOR IMPROVED COOLING
}

\author{
Syed Faisal Ahmed ${ }^{1}$, Dr Alka Bani Agarwal $^{2} \&$ Dr Sanjay Srivastava ${ }^{3}$
}

\begin{abstract}
The main problem of braking and stopping a bike is the extraordinary input of heat flux into the disc in a very short time. In the braking process, thermal stresses are generated by the frictional heat and thermal fatigue cracks appear due to the thermal stress on a braking surface. To improve disc brake cooling performance we propose a new design in ventilated brake disc. Also as there is a demand for lighter material, a newly developed stir casted master alloy (A190\% Ti5\% Cr5\%) has been proposed to be used as an alternative to conventional cast iron. Results of Thermal stress analysis of a aerofoil shaped ventilated cast iron disc have been compared with new proposed alloy disc with hexagonal shaped cut section and results has been encouraging. Both steady-state and transient simulations are performed using ANSYS CFX 14.5 based on the finite volume method and the time marching algorithm. The wear rate, coefficient of friction and contact pressure are derived from experimental measurements and applied to the computational designed model of the rotor. Both brake discs exhibit a similar temperature during initial period, while lower temperature is achieved by the new brake disc under steady-state conditions due to 1.82 times increase in heat transfer area caused by the hexagonal sections. Therefore Al MMC $(80 \% \mathrm{Al} 5 \% \mathrm{Ti} 5 \% \mathrm{Cr}$ with $10 \% \mathrm{SiC}$ ) with proposed hexagonal cut sectioned disc is most suitable for disc brake.
\end{abstract}

Keywords: Disc Brake, Alloy Al MMC, Static and couple structural analysis, Aerofoil shaped ventilated disc, Hexagonal cut sectioned disc.

\section{INTRODUCTION}

Disc brakes are widely used in automobiles because of good braking stability, controllability and the ability to provide a wideranging brake torque. The main problem of braking and stopping a bike is the extraordinary input of heat flux into the disc in a very short time. In the braking process, thermal stresses are generated by the frictional heat and thermal fatigue cracks appear due to the thermal stress on a braking surface. Due to high temperature difference, the brake discs are exposed to large thermal stress during routine braking and remarkable thermal stresses during emergency braking [1,2]. Numerous studies have revealed that such overheating can result in or aggravate brake fade [3-6], increased wear of friction pair [7], brake disc coning and thermal fatigue cracking [8-11], as well as thermal judder of the brake system [12,13]. Therefore, sufficient cooling of the brake disc is crucial to ensure brake reliability and comfort, especially for higher performance passenger vehicles.

To effectively remove the transferred heat, brake discs are often designed to have an additional ventilated channel configured by two rubbing discs that sandwich various heat dissipation elements. These centrifugal fan-like ventilated brake discs draw ambient air into the ventilated channel when the brake disc rotates [14]. Compared to a solid brake disc, substantially improved cooling can be achieved due to forced convection through the core elements [15]. Numerous studies have been conducted to improve the cooling performance of brake discs by modifying the cross-section and arrangement of radial vanes [16-24]. Although the cooling performance of the brake discs can be improved, constraints by the casting method make it difficult to optimize every aspect of the design. Pin-fins and vanes in current ventilated brake discs are prismatic and thick, configured two-dimensionally normal to the rubbing discs. This configuration may not be favorable for forced convective heat transfer due to limited flow mixing and heat transfer area. Such a situation motivated us to introduce hexagonal shaped cut sections into a ventilated brake disc to further improve its cooling performance.

In addition to heat removal capability, the core elements distributed in the ventilated channel must be sufficiently stiff and strong. In present day bikes, speed restriction continues to expand. Hence, the increase in bike speeds requires the improvement of the braking performances with light weight rotors. The existing cast iron disc brake rotor, although having a better braking efficiency is heavier and emits more particulate matter during braking. In this work, developed material $\mathrm{Al}$ 90\% Ti 5\% Cr 5\% master alloy (Al MMC) is reinforced with (0-10\% by wt) of silicon carbide (SiC) [25]. Thermal deformation, heat flux and von-misses stress distributions of the proposed disc brake have been investigated. The wear rate, coefficient of friction and contact pressure are derived from experimental measurements and applied to the computational

\footnotetext{
${ }^{1}$ Associate Professor, Department of Mechanical Engineering, Sagar Institute of Research and Technology Excellence, Bhopal, India

${ }^{2}$ Professor, Department of Mechanical Engineering, University Institute of Technology, RGPV, Bhopal, India

${ }^{3}$ Professor, MSME Department, Maulana Azad National Institute of Technology, Bhopal, INDIA.
} 
model of the brake. Couple structural analysis in ANSYS CFX 14.5 for existing and proposed design is compared. The best combination of design for bike disc brake like wall thickness, number of bolts and material is suggested.

\section{METHODOLOGY}

\subsection{Selection of material.}

Choosing the brake disc material has a crucial effect on the brake disc engineering. If the brake material has low thermal conductivity, the temperature gradient across the brake disc width will be high. As a result, the surface temperature will rise faster than the brake disc body, resulting in different thermal expansions between the surface and body of the brake disc. If these thermal induced stresses exceed beyond a certain magnitude or they repeat many times, brake disc failure is expected.

Proposed material of Aluminium matrix composite (Al MMC) is prepared by stir die casting which is a unique technique because of its simplicity and economy in processing [26]. Al MMC reinforced with varying percentage by weight of $\mathrm{SiC}$ is considered as potential candidate material due to its light weight and improved thermo mechanical properties for brake application. This process involves a liquid state fabrication technique which requires the incorporation of reinforcing phase (discontinuous form) into a molten matrix metal (continuous form) to obtain a uniform distribution through stirring [27-30].

\subsection{Comparison of cast iron properties with new proposed material}

Proposed material of Aluminium matrix composite (Al MMC) was prepared having $\mathrm{Al}$ 90\% $\mathrm{Ti}$ 5\% Cr 5\%. It was reinforced with $10 \%$ of $\mathrm{SiC}$ and its thermo-mechanical properties have been compared with cast iron and given in Table 1'

Table 1: Composition for AlTiCr Metal matrix composite with different reinforcements.

\begin{tabular}{cccccc}
\hline $\mathbf{S}$ No & Sample Designation & \multicolumn{1}{l}{$\mathbf{S i C}$} & \multicolumn{1}{l}{$\mathbf{T i}$} & $\mathbf{C r}$ & \multicolumn{1}{l}{ Al } \\
\hline $\mathbf{1}$ & AlTiCr $\left(\mathbf{S}_{\mathbf{0}}\right)$ & $0 \%$ & $5 \%$ & $5 \%$ & Rest \\
$\mathbf{2}$ & $\mathbf{S}_{\mathbf{1}}$ & $2 \%$ & $5 \%$ & $5 \%$ & Rest \\
$\mathbf{3}$ & $\mathbf{S}_{\mathbf{2}}$ & $4 \%$ & $5 \%$ & $5 \%$ & Rest \\
$\mathbf{4}$ & $\mathbf{S}_{\mathbf{3}}$ & $6 \%$ & $5 \%$ & $5 \%$ & Rest \\
$\mathbf{5}$ & $\mathbf{S}_{\mathbf{4}}$ & $8 \%$ & $5 \%$ & $5 \%$ & Rest \\
$\mathbf{6}$ & $\mathbf{S}_{\mathbf{5}}$ & $10 \%$ & $5 \%$ & $5 \%$ & Rest \\
\hline
\end{tabular}

\section{DESIGN ANALYSYS}

\subsection{Physical parameters used in analysis.}

The physical parameters of road bike disc brakes used for ANSYS analysis are represented in table 2.

Table 2: Physical parameters used in present analysis.

\begin{tabular}{ll}
\hline Parameter & Value \\
\hline Mass of the vehicle & $120 \mathrm{~kg}$ \\
Initial velocity $(\mathrm{u})$ & $27.7 \mathrm{~m} / \mathrm{s}$ \\
Vehicle speed at the end of the braking application $(\mathrm{v})$ & $0 \mathrm{~m} / \mathrm{s}$ \\
Brake rotor diameter & $0.262 \mathrm{~m}$ \\
Inner diameter & $0.130 \mathrm{~m}$ \\
Axle weight distribution 30\% on each side $(\gamma)$ & 0.3 \\
Percentage of kinetic energy that disc absorbs $(\mathrm{k})$ & $90 \%$ \\
Acceleration due to gravity $(\mathrm{g})$ & $9.81 \mathrm{~m} / \mathrm{s}^{2}$ \\
Coefficient of friction for dry pavement $(\mu)$ & 0.7 \\
Deceleration (a) & $-4 \mathrm{~m} / \mathrm{s}^{2}$ \\
Surface area on disc swept by pad $($ Ad) & $232.28 \mathrm{~mm}^{2}$ \\
\hline
\end{tabular}

\subsection{Calculation for input design parameters}


The general heat equation is briefly reviewed and the basic analysis strategy for the coupled thermo-mechanical system is described based on staggered approach. Uniform pressure and uniform wear are the available methods for calculating disc brake heat generation. In this study it is considered that pad was used several times. The uniform wear between pad and brake disc is stabilized, so the heat flux is just a function of time and it is independent of the space variable [31]. Hence uniform pressure theory was applied in this work.

The heat flux in a rotor model is calculated for the bike moving with a velocity $27.77 \mathrm{~m} / \mathrm{s}(100 \mathrm{kmph})$. For a vehicle decelerating on a level surface from a initial velocity $V_{1}=100 \mathrm{~km} / \mathrm{hr}$ to a final velocity $\mathrm{V}_{2}=0$ the braking energy $\left(\mathrm{E}_{\mathrm{b}}\right)$ was calculated as follows [32]

$E_{b}=\frac{1}{2} m\left(1+\frac{I}{R_{W}^{2} m}\right) V_{1}^{2}=\frac{1}{2} K_{c f} m V_{1}^{2}$

Where $\mathrm{I}$ is the mass moment of inertia of rotating parts, $\mathrm{m}$ is locomotive mass, $\mathrm{kcf}$ is the correction factor for rotating masses and $\mathrm{R}_{\mathrm{w}}$ is the wheel radius.

Braking power $\mathrm{Pb}$ is equal to braking energy divided by the time $\mathrm{t}$ during which braking occurs; for a constant declaration. It was calculated by equation 2 [32]

$P_{b}=\frac{d E b}{d t}=k_{c f} m_{a}\left(V_{1}-a t\right)$

Where ' $a$ ' is the deceleration of road bike and ' $t$ ' is the time period. As an example, in the case of emergency braking condition at $100 \mathrm{~km} / \mathrm{hr}$, the maximum stopping distance is $55.18 \mathrm{~m}$ with an average deceleration of $4 \mathrm{~m} / \mathrm{s}^{2}$.Corresponding dissipated energy is $3.1334 \mathrm{KJ}$ per braking.

Calculation for Heat Flux $(\mathrm{Q})$ : Heat Flux is defined as the amount of heat transferred per unit area per unit time, from or to a surface. It was calculated by equation 3 mentioned below:

$Q=P b / A$

Heat flux obtained from equation 3 was $35.24 \mathrm{k} \mathrm{W} / \mathrm{m}^{2}$

Generally the thermal conductivity of the brake disc is greater than that of brake pads material. Hence it can be considered that the total amount of the braking heat will be completely absorbed by the brake disc. This assumption leads to higher temperature estimation for brake disc. To avoid this, the pad and brake can be considered as semi-infinite solids and the heat generation ratio can be calculated as follows:

$\lambda=\frac{q_{d}}{q_{p}}=\left(\frac{\rho_{d} c_{d} k_{d}}{\rho_{p} c_{p} k_{p}}\right)^{1 / 2}$

where $\lambda$ is the heat generation ratio, $q_{d}$ is the heat flux absorbed by the brake disc, $q_{p}$ is the heat flux absorbed by the pad, $\rho$ represents density, $\mathrm{C}$ is the specific heat, $\mathrm{k}$ is the thermal conductivity and the subscript $\mathrm{d}$ and $\mathrm{p}$ indicate disc and pad, respectively.

Using equations (3) and (4), the heat flux on the braking surface can be found as follows:

$q_{d}=\frac{\lambda}{A(\lambda+1)} k_{c f} m a\left(V_{1}-a t\right)$

where $\mathrm{A}$ is the disc and pad contact area.

3.3 Modeling parameter and boundary conditions.

The transient test simulates continuous downhill braking at a constant vehicle speed. To this end, the brake disc is first accelerated to 800 RPM. Then the heating elements are switched on. Temperature field on the inboard copper foil surface is recorded every $60 \mathrm{~s}$ until steady-state heat transfer is approached. On the other hand, the steady-state tests aim to clarify the cooling performance of the brake disc at various rotational speeds from 200 RPM to 1000 RPM, corresponding to typical vehicle speeds of 25 to $124 \mathrm{~km} / \mathrm{h}$. For these tests, only the steady-state temperature field is measured. Detailed operating conditions of the experiments are summarized in table 3.

Table 3:Modeling parameter and boundary conditions.

\begin{tabular}{ll}
\hline Parameters & Value \\
\hline Rotor thickness existing and proposed & $4 \mathrm{~mm}$ and $6 \mathrm{~mm}$ \\
Rotor disc material existing & Gray cast iron or Ni-Cr steel \\
\hline
\end{tabular}




\begin{tabular}{ll}
\hline \hline Specific Heat Capacity & $447 \mathrm{~J} / \mathrm{kg} / \mathrm{deg} / \mathrm{C}$ \\
Coefficient of friction (Wet) & $0.08-0.12$, \\
Coefficient of friction (Dry) & $0.2-0.5$, \\
Maximum temperature & $250^{\circ} \mathrm{C}$, \\
Maximum pressure & $1 \mathrm{Mpa}$ \\
Force on pads & $140 \mathrm{~N}$ on pads. \\
Pressure on each pad & $025 \mathrm{Mpa}$ on $1 \mathrm{pad}$ \\
Surface area of one pad. & $2780.393 \mathrm{~mm}^{2}$ \\
Rpm & $420 \mathrm{rpm}$ \\
Heat flux on braking surface & $35.42 \mathrm{KW} / \mathrm{m}^{2}$ on each side \\
Convection Coefficient $(\mathrm{H})$ & $60 \mathrm{~W} / \mathrm{m}^{2} \mathrm{deg} \mathrm{K}^{-\ldots . . .}$ \\
Convection on free surface & \\
Air temp & $25 \mathrm{deg} \mathrm{C}$ \\
\hline
\end{tabular}

\section{STRUCTURAL AND COUPLE THERMAL ANALYSIS.}

4.1 Static structural analysis for existing cast iron and proposed alloyA static structural analysis determines the displacements, stresses, strains, and forces in structures or components caused by loads that do not induce significant inertia and damping effects. Steady loading and response conditions are assumed that is, the loads and the structure's response are assumed to vary slowly with respect to time.

Distortion energy theory is the most preferred failure theory used in industry. It is clear from above discussions that whenever an engineer resorts to distortion energy theory he can use Von-misses stress as a failure criterion perspective. Von-Misses theory is more popular due to its approach of treating failure criteria from the energy. In present work, thermal analysis of the wheel-mounted brake disc of $180 \mathrm{cc}$ bike is done. The driving force is supplied using a single cylinder petrol engine with a maximum speed of $120 \mathrm{~km} / \mathrm{h}$. This bike is designed to carry two passengers. Passenger bike has two wheels where front wheel is mounted with brake discs arranged on one side of a wheel and are bolted together through the wheel web (Fig. 1a). Forces acting on rotor during braking (Fig.1b) and dimensioned model (fig 1c) are shown in figure 1.
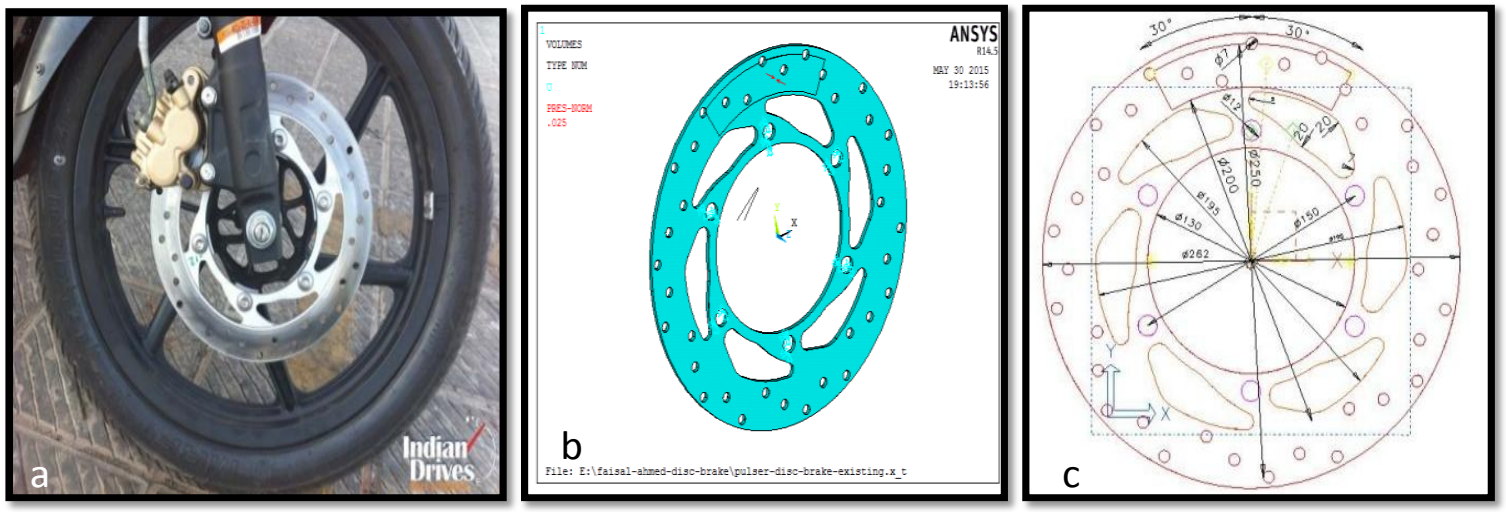

Figure 1: Road bike brake rotor (a), Forces acting on rotor during braking (b), Dimensioned model (c).

Static Structure analysis for existing road bike brake material was done using ANSY14.5 and values of mass, deformation and stresses are summarized in table 5. Static structural analysis values of existing brake material are mass $0.871 \mathrm{~kg}$, deformation $1.26 \mathrm{E}^{-04}$ Von-misses stress $0.7057 \mathrm{MPa}$, and for new alloy sample having same thickness mass $0.3811 \mathrm{~kg}$, deformation $7.29 \mathrm{E}^{-05}$ Von-misses stress $0.31107 \mathrm{MPa}$. It is apparent that with same disc thickness, mass and von-misses stresses values for new alloy sample is more appropriate.

\subsection{Couple structural analysis of existing cast iron (CI) and proposed alloy}

A coupled thermal and structural analysis is done to check the factor of safety of the material or the component under thermal as well as structural loading conditions. It is apparent from coupled analysis of existing brake disc that maximum von misses stresses (360.962 mpa) are observed near bolt and thermal deformation of 0.214091 between pads and ventilating hole. This leads to demand for reducing number of bolts on rotor disc with effective ventilation. Hexahedral meshing, thermal deformation and Von-misses stress of existing cast iron is shown in figure 2 

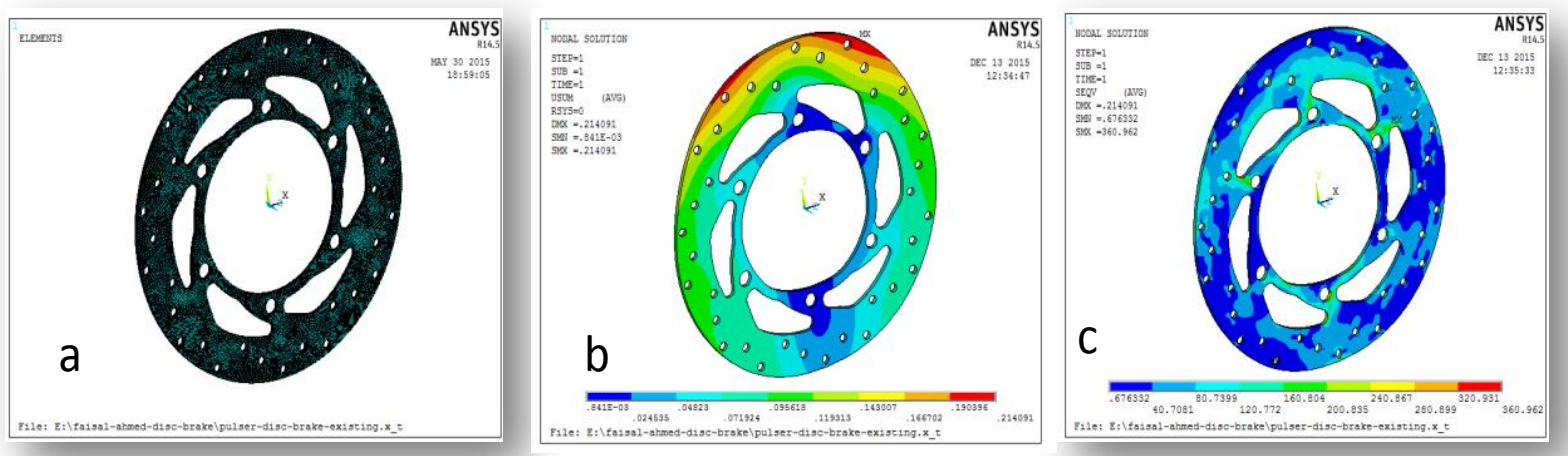

Figure 2: a) Hexa hedral meshing, b) Thermal deformation c) Von misses stress for existing CI disc.

From structural and couple thermal analysis it is apparent that values of deformation and von misses stresses for CI is better than new material having same disc thickness i.e. $4 \mathrm{~mm}$ only improvement of mass was observed, refer table 5 and 6 first 2 rows. Further improvement in deformation and von misses stresses leads us for demand of improved design in brake disc.

For the hexagonal cut section brake disc, in particular, one row of circular holes with identical diameter $(\mathrm{dh}=10 \mathrm{~mm})$ are drilled through both rubbing discs, as shown in Figure. 3 In total, 6 holes are drilled on each rubbing disc, with 10 hexagonal sections having $25 \mathrm{~mm}$ inner diameter is equally placed. These sections are arranged in an inline pattern along the radial direction. Rectangular V shaped notches/latices cut in between each hexagonal sections. Azimuthally, each hexagon section is located at the center of each cooling passage formed by two neighbouring rectangular notches having width of $5 \mathrm{~mm}$. Detailed geometric parameters of the brake discs are depicted in Figure. $\mathbf{3}$ and summarized in table 4.

Table 4: Geometric parameters of proposed design.

\begin{tabular}{|c|c|c|c|}
\hline Parameter & Value & Parameter & Value \\
\hline R1 & $131 \mathrm{~mm}$ & D1 & $25 \mathrm{~mm}$ \\
\hline R2 & $97.5 \mathrm{~mm}$ & D2 & $12 \mathrm{~mm}$ \\
\hline R3 & $75 \mathrm{~mm}$ & Notch T & $5 \mathrm{~mm}$ \\
\hline R4 & $65 \mathrm{~mm}$ & Notch L & $15 \mathrm{~mm}$ \\
\hline R5 & $35 \mathrm{~mm}$ & R6 & $40 \mathrm{~mm}$ \\
\hline
\end{tabular}

where $\mathrm{R} 1$ to $\mathrm{R} 6$ are radii. and D1,D2 are diameters.

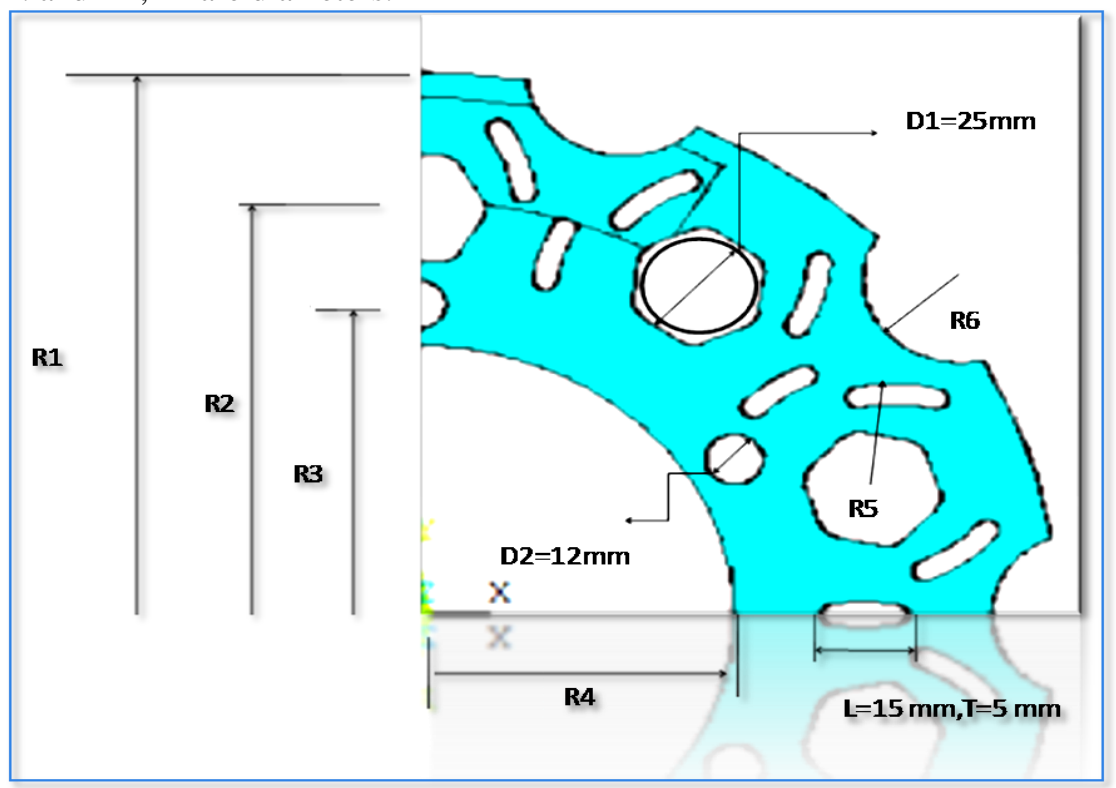

Figure 3: Proposed geometric design of disc brake

Couple field thermal structural analysis of proposed brake disc was conducted. Maximum temperature, von misses stress and deformation for braking of existing and proposed design during couple field analysis is summarised in Table 6. Disc design contours in deformation, temperature and von-misses stress are shown in figure 4 with disc thickness of $4 \mathrm{~mm}$. Since the demand was to reduce number of bolts ie from 6 to 5 which in turn reduces ventilation effect so we proposed hexagonal shape 
in place of existing aerofoil type shape so as to increase area of ventilation of disc. By doing so area for ventilation increased by $1.82 \%$.
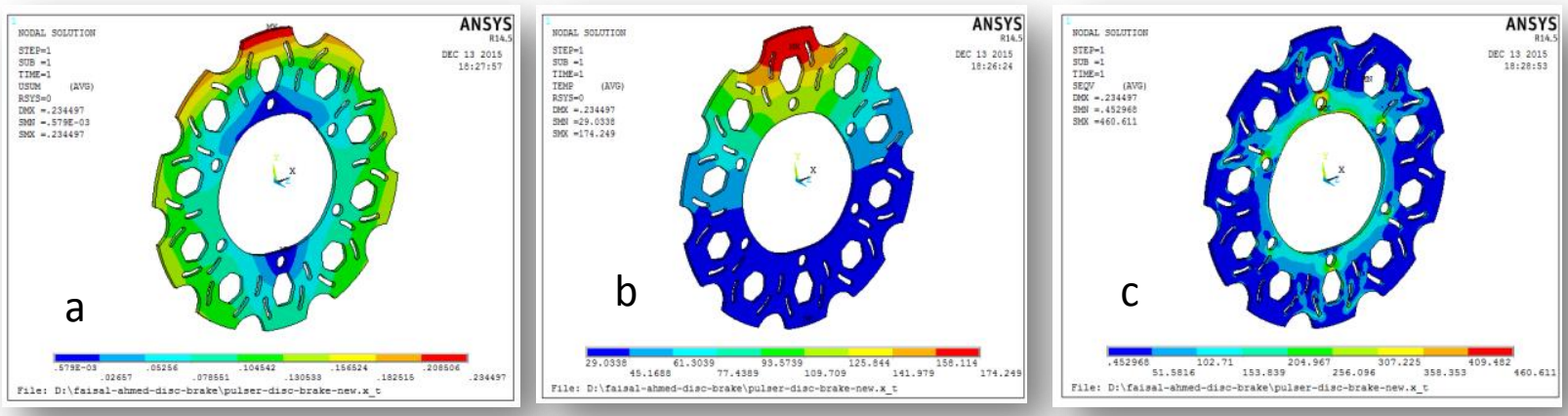

Figure 4: Proposed design contours in deformation (a) Temperature (b) and Von-misses stresses (c) with Al-MMC materials $\mathrm{SiC} 10 \%, \mathrm{~T}=4 \mathrm{~mm}$ with 6 bolt

\section{RESULTS AND DISCUSSIONS}

\subsection{Mesh convergence}

For finite element analysis (FEM), three-dimensional (3D) constructions of brake disc were modelled. Mesh independence was investigated and finally a mesh of 104896 elements and 139150 nodes were generated with disc thickness of $4 \mathrm{~mm}$. With same thickness and 6 bolts, mesh convergence of 51700 elements and 34839 nodes for thermal analysis was obtained. Element size was decreased from 10 to 1.5 in a hexa hedral meshing and mesh convergence was obtained for temperature, deflection and von mises stress.figure 5

From the analysis it is apparent that maximum deformation and temperature occur near brake pads where friction force is maximum but von-misses stresses are localized near bolts. Hence we tried to reduce number of bolts inorder to reduce possibility of failure during braking. For ANSYS, three-dimensional (3D) constructions of proposed brake disc and cooling air domain were meshed as shown in Figure 6.

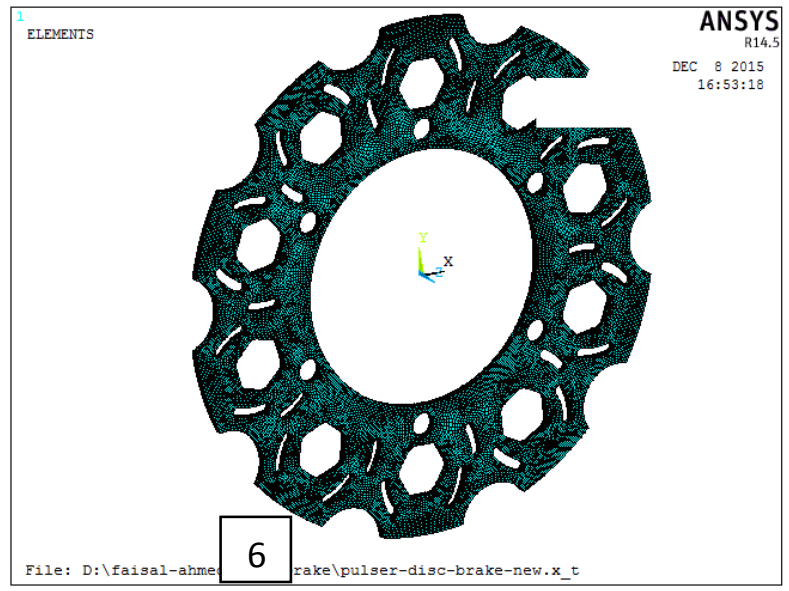

Figure.5: Showing meshing of proposed design 

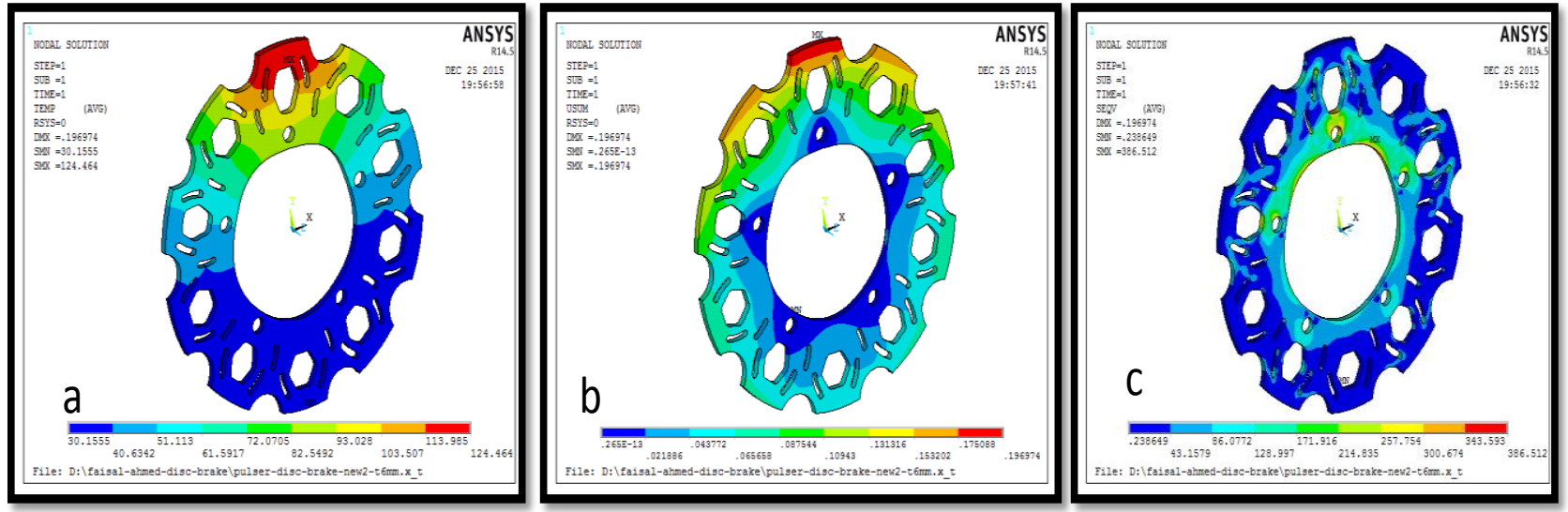

Figure 6: Proposed design contours in temperature (a), deformation (b) and Von-misses stresses (c) With Al-MMC materials $\left(\mathrm{S}_{5}\right) \mathrm{SiC} 10 \%, \mathrm{~T}=6 \mathrm{~mm}$ with 5 bolt.

Results obtained from static structural analysis proves that values of mass, deformation and von-misses stresses in new design with disc thickness $6 \mathrm{~mm} 5$ bolts is improved to a great extent as compared to those of Cast iron as shown in table 5 .

Table 5: Results of Structure analysis of existing road bike and proposed new material.

\begin{tabular}{c|cccccc}
\hline Disc brake type & Material & Mass kg & $\begin{array}{c}\text { Deformation } \\
\mathrm{mm}\end{array}$ & $\begin{array}{c}\text { Von-mises } \\
\text { stress(Mpa) }\end{array}$ & $\begin{array}{c}\text { Number Of } \\
\text { nodes }\end{array}$ & $\begin{array}{c}\text { Number } \\
\text { of-element }\end{array}$ \\
\hline $\begin{array}{c}\text { Existing design } \\
\text { T-4mm }\end{array}$ & Cast iron & 0.871061 & $1.26 \mathrm{E}^{-04}$ & 0.705734 & 139150 & 104896 \\
$\begin{array}{c}\mathrm{SiC} 10 \%(\mathrm{~T}- \\
4 \mathrm{~mm} 6 \mathrm{~B})\end{array}$ & $\begin{array}{c}\text { New proposed } \\
\text { AlMMC,T=4mm }\end{array}$ & 0.381177 & $7.29 \mathrm{E}^{-05}$ & 0.311076 & 139150 & 104896 \\
$\begin{array}{c}\text { New design T- } \\
\text { 4mm 6B }\end{array}$ & New ,T=4 mm & 0.35222 & $1.95 \mathrm{E}^{-05}$ & 0.09079 & 127710 & 94504 \\
$\begin{array}{c}\text { New design T- } \\
\text { 6mm 5B }\end{array}$ & New , T=6mm & 0.52844 & $1.94 \mathrm{E}^{-05}$ & 0.089757 & 178024 & 141108 \\
\hline
\end{tabular}

$\mathrm{T}=$ Thickness of disc, $\mathrm{B}=$ No of bolts

Maximum temperature, von misses stress and deformation for braking of existing and proposed design during couple field analysis is summarised in Table 6. New Material with thickness $6 \mathrm{~mm} \& 5$ bolts is lightest of all, having lowest maximum temperature and thermal deformation.

Table 6: Comparison of mass, maximum temperature and von-misses stresses in couple field analysis

\begin{tabular}{|c|c|c|c|c|c|c|}
\hline Disc brake type & Material composition & $\begin{array}{l}\text { Max temp } \\
\text { (deg.C) }\end{array}$ & $\begin{array}{l}\text { Thermal } \\
\text { deformation } \\
(\mathrm{mm})\end{array}$ & $\begin{array}{l}\text { Thermal Von- } \\
\text { misses stress } \\
\text { (Mpa) }\end{array}$ & $\begin{array}{l}\text { Numbe } \\
\text { r of- } \\
\text { nodes }\end{array}$ & $\begin{array}{l}\text { Number } \\
\text { of- } \\
\text { element }\end{array}$ \\
\hline CI Disc T-4 mm 6b & Cast iron $(\mathrm{CI})$ & 406.726 & 0.214091 & 360.962 & 52076 & 35793 \\
\hline $\begin{array}{c}\mathrm{S}_{5} \text { Thickness, T- } 4 \\
\text { mm- } 6 \text { bolt }\end{array}$ & $\mathrm{SiC} 10 \% \mathrm{~T}=4 \mathrm{~mm} 6 \mathrm{~b}$ & 231.216 & 0.316471 & 609.542 & & \\
\hline $\begin{array}{l}\text { New design , } \mathrm{S}_{5} \mathrm{~T}- \\
4 \mathrm{~mm}-6 \mathrm{bolt}\end{array}$ & $\mathrm{SiC} 10 \% \mathrm{~T}=4 \mathrm{~mm} 6 \mathrm{~b}$ & 174.249 & 0.234497 & 460.611 & 51700 & 34839 \\
\hline $\begin{array}{l}\text { Proposed design } 1, \\
\text { (T-6mm-6-bolt) }\end{array}$ & $\mathrm{SiC} 10 \% \mathrm{~T}=6 \mathrm{~mm} 6 \mathrm{~b}$ & 136.052 & 0.193073 & 414.55 & & \\
\hline $\begin{array}{l}\text { Proposed design } 2, \\
\text { (T-6mm-5-bolt) }\end{array}$ & $\mathrm{SiC} 10 \% \mathrm{~T}=6 \mathrm{~mm} 5 \mathrm{~b}$ & 124.464 & 0.196974 & 386.512 & & \\
\hline $\begin{array}{l}\text { Improved } \% \text { of (T- } \\
6 \mathrm{~mm}-5 \text { bolt) with } \\
\text { respect to CI }\end{array}$ & & 69.399 & 7.995 & -7.078 & & \\
\hline
\end{tabular}

$\mathrm{CI}$ is cast iron, $\mathrm{T}$ indicates thickness. 


\section{CONCLUSIONS:}

In this work we have studied static structural analysis and coupled thermal behaviour of existing and proposed ventilated disc. By the means of ANSYS CFX 14.5 we were able to study the thermal deformation; von misses stresses and maximum temperature reached for existing cast iron and proposed alloy for a determined braking mode. In addition to the influence of ventilation of the disc, we also studied the influence of the braking mode on the thermal behavior of the discs brake. About the results in general it can be concluded that:

1. Static structural analysis of existing brake disc shows maximum von-misses stresses (360.962 mpa) near bolt and thermal deformation of 0.214091 between pads and ventilating hole.

2. The highest values for von-misses stresses, temperature and thermal deformation for proposed design (proposed alloy with disc thickness $6 \mathrm{~mm}$ and 5 bolts) in couple field analysis was found to be $124.464 \mathrm{deg}$ C, $0.1969 \mathrm{~mm}, 386.512 \mathrm{Mpa}$ closest to cast iron. By reducing number of bolts and increasing width of disc by $2 \mathrm{~mm}$, deformation and maximum temperature achieved was improved by $7.9 \%$ and $69.4 \%$. Therefore new alloy (80\% Al 5\% Ti 5\% Cr with $10 \% \mathrm{SiC}$ ) with proposed hexagonal cut sectioned disc is most suitable composite material for disc brake.

3. ANSYS 14.5 CFX results shows that hexagonal sections provide more effective ventilation in comparison to aerofoil sections thereby giving a superior cooling performance.

\section{Funding}

This research did not receive any specific grant from funding agencies in the public, commercial, or not-for-profit sectors.

\section{REFERENCES:}

[1] B. Ghadimi, F. Kowsary, M. Khorami, Thermal analysis of locomotive wheel-mounted brake disc, Appl. Therm. Eng. 51 (2013) $948-952$.

[2] E. Palmer, R. Mishra, J. Fieldhouse, J. Layfield, Analysis of air flow and heat dissipation from a high performance GT car front brake, SAE Technical Paper No. 2008-01-0820.

[3] M. Pevec, I. Potrc, G. Bombek, D. Vranesevic, Prediction of the cooling factors of a vehicle brake disc and its influence on the results of a thermal numerical simulation, Int. J. Automob. Technol. 13 (5) (2012) $725 \mathrm{e} 733$.

[4] K. Lee, Numerical prediction of brake fluid temperature rise during braking and heat soaking, SAE Technical Paper No. 1999-01-0483.

[5] I. Ahmed, P.S. Leung, P.K., Datta, Experimental investigations of disc brake friction, SAE Technical Paper No. 2000-01-2778.

[6] M.H. Cho, S.J. Kim, R.H. Basch, J.W. Fash, H. Jang, Tribological study of gray cast iron with automotive brake linings: the effect of rotor microstructure, Tribol. Int. 36 (7) (2003) 537-545.

[7] S. Anoop, S. Natarajan, S.P. Kumaresh Babu, Analysis of factors influencing dry sliding wear behaviour of Al/SiCp-brake pad tribosystem, Mater. Des. 30 (9) (2009) 3831-3838.

[8] T. Okamura, H. Yumoto, Fundamental study on thermal behavior of brake discs, SAE Technical Paper No. 2006-01-3203.

[9] T.J. Mackin, S.C. Noe, K.J. Ball, B.C. Bedell, D.P. Bim-Merle, M.C. Bingaman, D.M. Bomleny, G.J. Chemlir, D.B. Clayton, H.A. Evans, R. Gau, J.L. Hart, J.S. Karney, B.P. Kiple, R.C. Kaluga, P. Kung, A.K. Law, D. Lim, R.C. Merema, B.M. Miller, T.R. Miller, T.J. Nielson, T.M. O'Shea, M.T. Olson, H.A. Padilla,B.W. Penner, C. Penny, R.P. Peterson, V.C. Polidoro, A. Raghu, B.R. Resor, B.J. Robinson, D. Schambach, B.D. Snyder, E. Tom, R.R. Tschantz, B.M. Walker, K.E. Wasielewski, T.R. Webb, S.A. Wise, R.S. Yang, R.S. Zimmerman, Thermal cracking in disc brakes, Eng. Fail. Anal. 9 (1) (2002) 63-76.

[10] C.H. Gao, J.M. Huang, X.Z. Lin, X.S. Tang, Stress analysis of thermal fatigue fracture of brake disks based on thermo mechanical coupling, ASME J Tribol.129 (3) (2007) 536-543.

[11] T.K. Kao, J.W. Richmond, A. Douarre, Brake disc hot spotting and thermal judder: an experimental and finite element study 23 (3-4) (2000) 276-296.

[12] A. Belhocine, M. Bouchetara, Thermal behavior of full and ventilated disc brakes of vehicles, J. Mech. Sci. Technol. 26 (11) (2012) $3643-3652$.

[13] R. Limpert, An Investigation of Thermal Conditions Leading to Surface Rupture of Cast Iron Rotors, SAE Tech. Pap. Ser. (1972) 720447.

[14] J. Lan, J. Yan-li, Yu Liang, Su Nan, Y. Ding, Thermal analysis for brake disks of SiC/6061 Al alloy co-continuous composite for CRH3 during emergency braking considering airflow cooling, Trans. Nonferrous Met. Soc. 22 (2012) 2783-2791.

[15] A. Adamowicz, P. Grzes, Analysis of disc brake temperature distribution during single braking under non-axis symmetric load, Appl. Therm. Eng. 31 (2011) 1003-1012.

[16] D.J. Kim, Y.M. Lee, J.S. Park, C.S. Seok, Thermal stress analysis for a disk brake of railway vehicles with consideration of the pressure distribution on a frictional surface, Mater. Sci. Eng. A Structure. 483-484 (2008) 456-459.

[17] A. Belhocine, M. Bouchetara, Thermo mechanical modelling of dry contacts in automotive disc brake, Int. J. Therm. Sci. 60 (2012) $161-170$.

[18] A. Belhocine, M. Bouchetara, Thermal analysis of a solid brake disc, Appl. Therm. Eng. 32 (2012) 59-67.

[19] F. Talati, S. Jalalifar, Analysis of heat conduction in a disk brake system, Heat Mass Transf. 45 (2009) 1047-1059.

[20] Shorowordi KM, ASMA Haseeb, Celis JP. Velocity effects on the wear, friction and tribo-chemistry of aluminum MMC sliding against phenolic brake pad. Wear 2004;256:1176-81.

[21] Cueva G, Sinatora A, Guesser WL, Tschiptschin AP. Wear resistance of cast irons used in brake disc rotors. Wear 2003;255/7-12:1256-60.

[22] Daoud A, Abou El-khair MT. Wear and friction behaviour of sand cast brake rotor made of A359-20 vol\% SiC particle composites sliding against automobile friction material. Tribology International 2010; 43/3:544-53.

[23] Kennedy FE, Bahadur AC, Lashmore DS. The friction and wear of Cu-based silicon carbide particulate metal matrix composites for brake applications. Wear 1997;203-204:715-21.

[24] Gomes JR, Silva OM, Silva CM, Pardini LC, Silva RF. The effect of sliding speed and temperature on the Tribological behaviour of carbon-carbon composites. Wear 2001; 249/3-4:240-5.

[25] Faisal Ahmed, Sanjay Srivastava, Alka Bani Agarwal. Synthesis \& Characterization of Al-Ti-Cr MMC as friction material for disc brakes application, Materials Today: Proceedings Vol.4 issue 2; (2017) p 405-414 
[26] A. Rehman, S. Das, G. Dixit, Analysis of stir die cast Al-SiC composite brake drums based on coefficient of friction, Tribology International 51 (2012) $36-41$.

[27] Sallit I, Richard C, Adam R, Robbe-Valloire F. Characterization methodology of a tribological couple: metal matrix composites/brake pads. Material Characterization 1998; 40/3:169-88.

[28] Mosleh M, Blau PJ, Dumitrescu D. Characteristics and morphology of wear particles from laboratory testing of disk brake materials. Wear 2004;256/1112: $1128-34$

[29] Ravinder Kumar, Santram Chauhan. Study on surface roughness measurement for turning of Al 7075/10/SiCp and Al 7075 hybrid composites by using response surface methodology (RSM) and artificial neural networking (ANN), Measurement 65 (2015) 166-180

[30] Faisal Ahmed, Sanjay S, Alka B Aggarwal. Microstructure, Mechanical and Surface Morphological properties of Al5Ti5Cr master alloy as friction material prepared by stir die casting. Journal of The Institution of Engineers (India): Series D,2017 ISSN 2250-2122

[31] J.H. Choi, I Lee. Finite element analysis of transient thermo elastic behaviours in disc brakes, Wear 257(2004) 47-58.

[32] B. Ghadimi, R. Sajedi, F. Kowsary, 3D investigation of thermal stresses in a locomotive ventilated brake disc based on a conjugate thermo-fluid coupling boundary conditions, International Communications in Heat and Mass Transfer 49 (2013) 104-109. 